\section{EL SILENCIO DE LOS ANTROPÓLOGOS. HISTORIA Y ANTROPOLOGÍA: UNA AMBIGUA RELACIÓN}

\author{
Emanuele Amodio \\ Escuela de Antropología \\ Universidad Central de Venezuela, Caracas, Venezuela \\ Apartado 51088, Caracas 1050, Venezuela \\ E-mail:arinsana@gmail.com
}

\section{ANTHROPOLOGISTS' SILENCE. HISTORY AND ANTHROPOLOGY: AN AMBIGUOUS RELATION}

\begin{abstract}
The history of the relations between history and anthropology, present since the formation of these two disciplinary fields, has recorded periodical approaches and estrangements up to a point of stagnation within each academic realm. In order to find a common ground for confrontation, it is necessary to recover some of the links in this relation, based on the experience of each discipline in their specific research areas. Thus, in this paper some anthopological and historiographical approaches are analysed, convinced as we are that having both disciplines the same object of inquiry, although temporally phased out, the need for a dialogue between them becomes urgent, specially as a response to the menacing epistemological nihilisms that aim at thwarting both views.
\end{abstract}

KEY WORDS: Social history; anthropology; epistemology.

\section{Preliminar}

La posibilidad de reflexionar sobre las relaciones entre historia y antropología, ofrecida por este espacio de homenaje y reflexión a partir de la obra de Peter Burke, podría ser la ocasión propicia para presentar un estado del arte, como se decía una vez, si no fuera que esta posibilidad ha ido debilitándose con el tiempo y la globalización galopante nos ha vuelto conscientes que elaborar cuadros generales con algún valor empírico ya no es factible, particularmente porque no podemos continuar ignorando que circulan cada vez más informaciones, no necesariamente mediatizadas por las traducciones norteamericanas, sobre la relación disciplinar que nos ocupa en lugares hasta hoy no tomados en consideración como pueden ser la India, México o Italia.

Así, lo que queda es elegir un recorrido a partir de la propia experiencia disciplinar, investigadora y/o docente,
RESUMEN: La historia de las relaciones entre historia y antropología, presentes desde la formación de los dos campos disciplinarios, ha registrado acercamientos y alejamientos periódicos, hasta estancarse dentro de sus barreras universitarias. Por esto, para intentar encontrar un campo común de confrontación, se hace necesario recuperar algunos eslabones de la relación, a partir de la experiencia de cada uno en sus campos específicos de investigación. De esta manera, se analizan algunas posturas antropológicas e historiográficas para entender esta ambigua relación, en el convencimiento de que, siendo el objeto de ambas disciplinas el mismo, aunque desfasado temporalmente, el diálogo se vuelve urgente, sobre todo frente al embate de los nihilismos epistemológicos que avanzan sus pretensiones para desbaratar ambas miradas.

PALABRAS CLAVE: Historia social; antropología; epistemología.

matizándola con algunas lecturas de textos que uno recorta por elección consciente o por azar, por sintonía o necesidad. En este sentido, vale decirlo de antemano, la lectura de algunas escrituras de Peter Burke nos ha servido de aliciente, en los últimos veinte años, para continuar insistiendo en la trivialidad de las fronteras disciplinares $y$, al mismo tiempo, de sostén en las diarias actividades docentes, ya que algunos de sus textos han marcado definidamente las bibliografías obligatorias de mis cursos de antropología histórica en ese lejano Occidente que es Venezuela. Actividades académicas, éstas, que se realizan dentro de un espacio mirado con desconfianza tanto por mis colegas antropólogos como por mis amigos historiadores, lo que no debe ser muy diferente, salvando las diferencias, de lo vivido por Burke cuando, después de llegar a Cambridge en 1979, intentó con Bob Scribner organizar un curso de "antropología histórica" cuya aprobación el Comité académico pospuso más de una vez, convencido que había "demasiada teoría" en el programa propuesto'. 
Es precisamente esta desconfianza lo que aparece cuando se intentan recortar nuevos espacios disciplinares 0 , peor, eliminar barreras para unificar o ampliar otros ya establecidos. Así, ya que me intereso por una sociedad colonial específica del siglo XVIII, después de largos años de trabajo de campo entre sociedades indígenas americanas contemporáneas, para mis colegas antropólogos me he vuelto un historiador, perdiendo mi identidad profesional; mientras que para mis amigos historiadores, continúo siendo un antropólogo "metiche" o infiltrado, como bien repetía hace unos años una amiga francesa, historiadora de las mentalidades. Al fin, un traidor para los unos y un intruso para los otros.

Estas vivencias académicas, por la carga emocional que conllevan, a menudo impiden aclarar un problema histórico y epistemológico: la formación histórica de las disciplinas sociales, coherentes con el contexto social, económico y cultural de su producción, y la crisis que sufren una vez que cambia precisamente el terreno en las cuales se han desarrollado a lo largo de los últimos doscientos años. De hecho, antes que estilos de pensamiento y presupuestos teóricos diferentes, las barreras entre campos disciplinares son académicas, es decir, levantadas históricamente por esa máquina aglutinante que es la administración universitaria, experta en moler deseos y triturar voluntades. Véase, en este sentido, la distancia entre carreras como antropología e historia en muchas de nuestras universidades: la de antropología se incluye, generalmente, dentro de las facultades de ciencias sociales, mientras la de historia lo es en humanidades, lo que es claramente el resultado de un largo proceso de decantación de intereses, pero también de definición y demarcación de espacios de poder.

\section{Retrato de Familia, CON INVITAdOS...}

Es un hecho, un poco obvio, que la estructuración histórica local de las disciplinas dificulta diálogos y transversalidades, y se solapa con un problema un poco más complejo y resbaladizo que, de alguna manera, termina por justificar las barreras epistémicas: la segmentación de la realidad social en compartimentos más o menos estancos, dentro del proyecto ilustrado de conocimiento científico de la realidad que generó durante el siglo XIX y primera mitad del $X X$, a partir del modelo de la ciencias que con una metáfora poco feliz se ha dado en llamar duras, las "ciencias sociales", por un lado, y la "disciplina historiográfica", por el otro. Es evidente que la diferencia semántica entre "ciencia", aunque blanda, y "disciplina" pesa enormemente en las relaciones entre las diferentes "comunidades" de pensamiento; sin considerar que cada macro-comunidad se diferencia, en su interior, en subgrupos geográficos o temáticos, cada uno con su estilo, protocolos de investigación y medios de transmisión y control del saber producido.

Si ejemplos hay que hacer a este propósito, el del grupo de los Annales, estudiado y citado a menudo por Peter Burke (Burke, 1999), es ineludible ya que se presta magnificamente para ilustrar una historia particular de relaciones entre mundos epistémicos diferentes, que se ha vuelto modélica para inspirar nuevos recorridos investigativos $y$, también, como antecedente valorativo para la acción académica. Así, en la producción de las obras que están en el origen mismo de la nueva corriente historiográfica -el Felipe II de Febvre, El Mediterráneo de Braudel y Los Reyes Taumaturgos de Bloch- privó la influencia explícita del padre de la antropología francesa, Durkheim; de la misma manera que el paso de una histoire évènementielle a una estructural es coherente con el auge estructuralista, sobre todo antropológico. Precisamente Braudel, cuyo concepto de "larga duración" es, de hecho, una propuesta de temporalidad cultural que los antropólogos no deberian desdeñar, se dedicó a difundir la necesidad de una relación fructífera entre historia y ciencias sociales (Braudel, 1995), apuntando a la necesidad de estudios que abarcaran la "totalidad" de las vivencias sociales, así como Febvre y Mauss habian enseñado, cada uno desde perspectivas diferentes (Burke, 1999, 47). Sin embargo, es el acercamiento a Claude Lévi-Strauss, con quien Braudel integró la Misión Cultural francesa en la Universidad de Sao Paulo a mitad de los años treinta (Skidmore, 2003), lo que estructura la relación entre los dos campos disciplinares, sobre todo considerando que el difícil diálogo y las polémicas conceptuales que en la posguerra se produjeron tenían un referente espacial que le daba contexto implícito a la relación: la coexistencia en un mismo lugar académico, la École, sobre todo en ese momento mágico cuando por sus pasillos se cruzaban Lévi-Strauss y Barthes, Foucault y Braudel, cada uno arrastrando su cortejo de creyentes, gli uni contro gli altri armati. 
Queremos insistir sobre la presencia de Lévi-Strauss en nuestra "foto de familia" no sólo por la importancia que el padre del estructuralismo tiene para el campo disciplinar del cual provenimos, sino porque es común en quienes se han interesado en reconstruir la historia de estas relaciones disciplinares hacer referencia al funcionalismo inglés, dejando en segundo plano y hasta "olvidando" que las mayores discusiones, por los menos en la Europa continental de los años sesenta y setenta, se dieron a partir del estructuralismo. Véase la reconstrucción dramática que, con suficientes razones, elabora Peter Burke en la versión de 1980 de Sociology and History: "Entonces, repentinamente, alrededor del año 1920 los antropólogos y los sociólogos rompieron con el pasado" (Burke, 1987, 21). Y continúa:

"El antropólogo formado en Gran Bretaña Bronislaw Malinowski descubrió y proclamó la importancia del 'trabajo de campo', como él lo denominó; en otras palabras, la observación participante. Dicha observación participante no era completamente nueva; desde 1886 Boas había hecho largas visitas a los kwakiut/y Radcliffe-Brown vivió los años 1906-8 en las islas Andamán. Lo nuevo era la insistencia de Malinowski en el trabajo de campo como el método antropológico por excellence. 'El antropólogo', declaró, 'debe renunciar a su confortable posición en la mecedora del porche'. El trabajo de campo se convirtió en una fase necesaria de la formación de cada antropólogo. El nuevo método, como la historia de Ranke, era más científico; una forma más segura de estudiar las sociedades tribales contemporáneas que la historia evolutiva, en gran medida conjetural, que le habia precedido. Sin embargo, no podía aplicarse al pasado" (Burke, 1987, 22).

Dejando la última afirmación para más adelante, es evidente que no hubo una ruptura tan abrupta $y$, además, ésta nunca se consumó completamente, sobre todo considerando que se sumaban en un mismo reparo dos aspectos distintos de la cuestión. Antes que nada, el problema del método, y no de la simple técnica, en el contexto de un fuerte impulso positivista para "hacer ciencia", con una base epistemológica suficientemente sólida para permitir una verdadera comparación entre los "casos" estudiados, implicaba preguntarse tanto sobre la manera de recoger los datos (se necesitaban más expertos etnógrafos que misioneros y viajeros) ${ }^{2}$, como la atención sobre el tratamiento de los datos, es decir, el relato antropológico como protocolo de un "experimento" ex post facto.
El segundo aspecto de la cuestión resultaba más perturbante para la sensibilidad de los historiadores, tanto para los clásicos alemanes como para los modernos franceses, ya que ponía definitivamente en duda la importancia y hasta la existencia misma de su objeto de estudio. Así, volviendo al texto ya citado de Burke:

"Primero se le criticó a las explicaciones históricas que fueran especulativas, después se las rechazó por irrelevantes. Durkheim había combinado un método funcionalista con el interés por la historia, pero los funcionalistas posteriores, como Malinowski, abandonaron la historia completamente. Según él, el pasado estaba 'muerto y enterrado', y sólo importaba la imagen del pasado, porque esa imagen formaba parte de la 'realidad psicológica de hoy'" (Burke, $1987,23)^{3}$.

Sin embargo, hay que prestar atención a todo esto: los funcionalistas no negaban la pretérita existencia del pasado a la manera, por ejemplo, de algunos actuales postmodernos, sino que, en la búsqueda de leyes generales con valor universal, su teoría antropológica del funcionamiento de la sociedad los llevaba a deducirlas de la comparación entre formas sociales del presente, dejando en segundo plano la posibilidad de contrastarlas históricamente ${ }^{4}$. A este propósito, mucho antes de Malinowski, el padre de la definición de cultura, E. B. Taylor, anticipándose al mismo estructuralismo funcionalista, había dicho que "si de un conjunto de hechos puede inferirse una ley, el papel de la historia queda enteramente superado. Si vemos que un imán atrae un trozo de hierro y si hemos logrado extraer la ley general según la cual el imán atrae el hierro, no vale la pena que profundicemos en la historia del imán en cuestión" (Taylor, 1871; en Lévi-Strauss, 1995, 52). Sin embargo, mientras la lógica de la afirmación parece funcionar, lo que chirría es la transposición de los términos considerados al mundo de la vida social, porque, como bien observa Lévi-Strauss, "a diferencia del físico, el etnólogo sigue indeciso acerca de la posibilidad de identificar objetos que aparecen superficialmente como dos imanes o dos pedazos de hierro. Tan sólo una 'historia detallada' le permitiría en cada caso superar la duda" (Lévi-Strauss, 1995, 52).

Más allá de la defensa de la investigación historiográfica que el padre del estructuralismo antropológico hace, fueron los mismos continuadores de la obra de Malinowski quienes matizaron las posturas de sus maestros, como es 
el caso de Evans-Pritchard, quien a comienzo de los años cincuenta del siglo pasado abogaba por un cambio de actitud en la antropología inglesa, cuando remarcaba que las pequeñas comunidades de bajo grado de estructuración social forman parte siempre de "grandes sociedades históricas" y, por ende, su estudio diacrónico era posible, además de útil a la interpretación general (Evans-Pritchard, 1990, $14)^{5}$. Sin embargo, iba más allá de la simple constatación de esta posibilidad, llegando a la conclusión de que el estudio histórico, aunque a partir de materiales documentales indirectos, permitía un comprensión más amplia y profunda de la realidad investigada por los antropólogos. De allí que avanzaba la temprana hipótesis de delimitar, por un lado, un campo de estudio que ya llamaba historia social, mientras que, por el otro, la misma antropología social podría considerarse una "especie de historiografia", y a esta conclusión llegaba a partir precisamente de la homología de los recorridos investigadores historiográfico y antropológico: recolectar datos, anotar observaciones $y_{\text {, fi- }}$ nalmente, regresar al despacho para revivir "la experiencia crítica e interpretativamente de acuerdo con las categorias y valores de su propia cultura y con el cuerpo general de conocimientos de su disciplina. En otras palabras, traduce una cultura a otra" (Evans-Pritchard, 1990, 15). Así, en esta actitud interpretativa y traductora, historia y antropología harian lo mismo, la una para las sociedades "primitivas" del presente y la otra para las del pasado. El auspicio de una posible integración, donde cada disciplina aportaria su experiencia histórica y sus métodos característicos, es explícito:

\begin{abstract}
"Los historiadores pueden suministrar a los antropólogos sociales un inapreciable material, examinado y comprobado por técnicas críticas de verificación e interpretación. Los antropólogos sociales pueden proporcionar al historiador del futuro algunos de sus mejores informes, basados en observaciones cuidadosas y detalladas, y pueden también derramar sobre la historia, por medio del descubrimiento de modelos estructurales latentes, la luz de los universales. El valor que cada disciplina tiene para la otra pienso que será reconocido cuando los antropólogos se entreguen con más asiduidad a la erudición histórica y muestren cómo el conocimiento de la antropología ilumina con frecuencia los problemas históricos" (Evans-Pritchard, 1990, 19).
\end{abstract}

Dejando por ahora de lado la referencia a los "historiadores del futuro", que abre la senda de una discusión sobre la mirada desde adentro y la mirada desde afuera, lo que nos llama la atención en la postura conciliadora de EvansPritchard es su cercanía con la que, en esa misma época, tomaba en Francia Lévi-Strauss desde un estructuralismo que ya no pactaba con el funcionalismo ${ }^{6}$.

Es ampliamente conocido el impacto que tuvo para la antropologia y las ciencias sociales la publicación en 1958 de la recopilación de textos de Lévi-Strauss que lleva el nombre de Antropología Estructural, sobre todo el primer capítulo Etnología e historia, donde consigna de manera explícita su apreciación de la relación entre los dos campos disciplinares. Rechazando la perspectiva de los funcionalis-

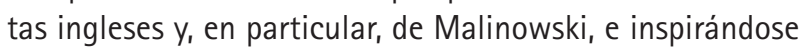
en la obra de Boas, Lévi-Strauss considera que aun siendo verdad que la ausencia de documentos impide en gran parte reconstruir la historia de los pueblos donde el saber se trasmite de manera oral, produciendo una abundancia de inferencias conjeturales, esto no debe necesariamente producir una postura extrema, renunciando a priori a intentarlo, y hasta teoriza su poca utilidad, "para transformar el estudio de las culturas en un análisis sincrónico de las relaciones entre sus elementos constitutivos en el presente". Al contrario, la pregunta que hay que hacerse es "si el más penetrante análisis de una cultura particular que abarque la descripción de las instituciones y de sus relaciones funcionales y el estudio de los procesos dinámicos por los cuales cada individuo obra sobre su cultura y la cultura sobre el individuo, puede adquirir todo su sentido sin el conocimiento del desarrollo histórico que ha desembocado en las formas actuales" (Lévi-Strauss, 1995, 57).

Resulta un poco chocante leer afirmaciones como la anterior por parte de quien ha sido considerado, por lo menos por la vulgata estructuralista, como el "negador" de la importancia de la historia para la descripción e interpretación de las sociedades del presente ${ }^{7}$. En verdad, y aquí estriba la equivocación, lo que era un debate sobre la posibilidad de historiar sociedades sin escritura -los kwakiutl de Boas, los trobriandeses de Malinowski o los nambiquara de LéviStrauss- se extendió, de manera más o menos maliciosa, al pasado de cualquier sociedad, generando equivocaciones y obvios rechazos, comenzando por el mismo Lévi-Strauss, para quien la distancia entre los métodos de las dos disciplinas no es tanta como la indicada por los funcionalistas (el trabajo de campo para los unos, el trabajo de archivo para los otros). En ambos casos se trata de estudiar sociedades 
diferentes de la propia, no importando si esta heterogeneidad cultural deriva de la distancia espacial o de la temporal, para "ampliar una experiencia particular hasta alcanzar las dimensiones de una experiencia más general que para esta misma razón resulta accesible como experiencia a hombres de otro país o de otro tiempo. Y ambos lo logran bajo las mismas condiciones: ejercicio, rigor, simpatia, objetividad" (Lévi-Strauss, 1995, 64). Evidentemente, entre la recolección presencial de los datos y la recopilación a través de documentos escritos o restos materiales, como en el caso de los arqueólogos, hay una diferencia que no puede solaparse, sobre todo considerando que las diferencias de materiales imponen técnicas de acopio diferentes, además que la presencia del investigador en el lugar de los hechos permite disminuir las mediaciones que presenta, por ejemplo, el relato histórico de un contemporáneo no entrenado.

Esta equivalencia de los dos tipos de actividad investigadora, es decir, el historiador como etnógrafo o viceversa, resulta muy cercana a la expresada por Evans-Pritchard más o menos una década después:

"Cuando el historiador fija su atención exclusivamente en una cultura particular y en un periodo determinado y limitado de su historia, produce lo que podriamos llamar una monografía etnográfica... Cuando, por otra parte, un antropólogo social escribe acerca del desarrollo en el tiempo de una sociedad, escribe un libro de historia, distinto, es verdad, de la historia narrativa y política corriente, pero en lo esencial el mismo que redactaria un historiador social" (Evans-Pritchard, 1990, 17-18).

Sin embargo, esta simple homologación no resiste mucho un análisis epistemológico, ya que unifica los objetos (la sociedad), aunque desplazados en el tiempo, y parece también unificar los métodos, aunque unos testimoniales y otros documentales; pero nada nos dice de la "mirada", es decir, a partir de cuál teoría del mundo se produce el interés del investigador $y$, sobre todo, la construcción de su objeto. Y esto porque un mismo objeto puede adquirir significado y sentido diferente precisamente a partir de una diferente mirada dentro de un mismo campo disciplinar y más aún cuando se trata de campos diferentes. Pienso que Lévi-Strauss fue consciente de esta problemática y de hecho su planteamiento sucesivo puede considerarse una solución posible, por lo menos desde la perspectiva antropológica estructuralista:
"Pero el paralelismo metodológico que se pretende trazar entre etnografía e historia para oponer la una a la otra es ilusorio. El etnógrafo es un individuo que recoge los hechos y los presenta (si es un buen etnógrafo) de acuerdo a las mismas exigencias que rigen para el historiador. El papel del historiador consiste en utilizar estos trabajos cuando las observaciones, escalonadas a lo largo de un período suficiente de tiempo, se lo permiten; éste es también el papel del etnólogo, cuando observaciones de un mismo tipo, relativas a un número suficiente de regiones distintas, lo hacen posible. En todos los casos, el etnógrafo establece documentos que pueden ser útiles al historiador. $Y$ si los documentos existen ya, y el etnógrafo decide integrar su trabajo con la sustancia de los mismos, ¿no debe acaso el historiador envidiarle el privilegio -a condición, naturalmente, de que el etnógrafo tenga un buen método histórico- de hacer historia de una sociedad de la cual posee una experiencia vivida?" (LéviStrauss, 1995, 65).

La utilización del trabajo etnográfico por parte de los historiadores, esta vez no del futuro, como había indicado Evans-Pritchard, sino del presente, tendría su contrapartida en la toma en consideración de las "reconstrucciones" historiográficas por parte del etnógrafo. De esta manera, y si esto fuera todo, el aporte de Lévi-Strauss, aunque más sofisticado, no iría más allá de las exhortaciones genéricas de antropólogos e historiadores que, durante la segunda mitad del siglo XX, se han dedicado a auspiciar la existencia de canales de comunicación entre las dos disciplinas, sin considerar en absoluto el problema de la diferencia entre las epistemologías que definen estas dos disciplinas. Al contrario, nos parece que ésta es precisamente la dirección indicada por Lévi-Strauss.

En la cita anterior llama la atención que, después de indicar la utilidad que los informes etnográficos pueden tener para los historiadores, Lévi-Strauss añade que lo mismo ocurre con los etnólogos. La entrada en escena de este tercer personaje, presuntamente homólogo del historiador, complica el panorama y perturba la genérica y general exhortación de fraternidad, pero permite aclarar el problema epistemológico: ¿Cuál es la diferencia entre un etnógrafo y un etnólogo y por qué es tan importante en el contexto de la propuesta estructuralista? En palabras del mismo antropólogo francés, "la etnografía consiste en la observación y el análisis de grupos humanos considerados en su particularidad... y que busca restituir, con la mayor fideli- 
dad posible, la vida de cada uno de ellos, mientras que la etnología utiliza de manera comparativa... los documentos presentados por el etnógrafo" (Lévi-Strauss, 1995, 50). En este sentido, la etnología correspondería a la anglosajona antropología social y cultural. Son precisamente estos dos niveles o fases del trabajo antropológico los que permiten a Lévi-Strauss articular las relaciones entre historia y antropología: "Teniendo el mismo objeto, que es la vida social, el mismo propósito, que es una mejor comprensión del hombre, y un método que sólo varia en cuanto a la dosificación de los procedimientos de investigación, se distinguen sobre todo por la elección de perspectivas complementarias: la historia organiza sus datos en relación con las expresiones conscientes de la vida social, y la etnología en relación con las condiciones inconscientes" (Lévi-Strauss, 1995, 65-66).

Lo que podria parecer un argucia digna de un prestidigitador, en el contexto de nuestra discusión aparece como un verdadero aporte teórico. Lévi-Strauss asume y lleva a su lógica consecuencia la koiné que constituye el centro medular de la representación del mundo de la modernidad: que la vivencia humana está constituida por diferentes niveles de existencia, algunos de los cuales funcionan de manera inconsciente, y es precisamente este "opacamiento" lo que permite el funcionamiento de individuos y sociedades, desde la producción de identidades culturales y étnicas, hasta la puesta en práctica automática de las reglas sociales. Así, éste sería el objetivo de la etnología:

"Su objetivo consiste en alcanzar, más allá de la imagen consciente y siempre diferente que los hombres forman de su propio devenir, un inventario de posibilidades inconscientes, cuyo número no es ilimitado: el repertorio de estas posibilidades y las relaciones de compatibilidad e incompatibilidad que cada una de ellas mantiene con todas las demás proporcionan una arquitectura lógica a desarrollos históricos que pueden ser imprevisibles sin ser nunca arbitrarios. En este sentido, la célebre fórmula de Marx: 'los hombres hacen su propia historia, pero no saben que la hacen' justifica, en su primer término la historia, y en su segundo término, la etnología. Al mismo tiempo muestra que ambos caminos son indisociables" (Lévi-Strauss, 1995, 70).

Así, derivando de la teoría de la alienación de Marx y, sobre todo, de la psicología freudiana, el padre del estructuralismo propone diferenciar antropología y disciplina histórica a partir de una diferenciación de objeto y de mirada, es decir, de carácter epistemológico. Será precisamente este último aspecto el que socavará, de alguna manera, la propuesta. De hecho, en cuanto al método, Lévi-Strauss se pregunta cómo alcanzar esas estructuras inconscientes, ya que, para él, de eso se trata:

¿Cómo llegar a esta estructura inconsciente? Aquí convergen el método etnológico y el método histórico. Resulta inútil invocar en este caso el problema de las estructuras diacrónicas, para las cuales los conocimientos históricos son evidentemente indispensables. Ciertos desarrollos de la vida social traen consigo sin duda una estructura diacrónica, pero el ejemplo de la fonología enseña a los etnólogos que este estudio es más complejo -y plantea otros problemas- que el de las estructuras sincrónicas que ellos apenas comienzan a emprender. Sin embargo, inclusive el análisis de las estructuras sincrónicas implica un constante recurrir a la historia. Únicamente ésta permite extraer, al poner de manifiesto instituciones que se trasforman, la estructura subyacente a formulaciones múltiples" (Lévi-Strauss, 1995, 68-69).

Ahora, más allá de esta necesaria complementariedad, para Lévi-Strauss los dos recorridos investigadores se cruzan doblemente: la historia avanza desde lo explícito hacia lo implícito, mientras la etnología de lo particular hacia lo universal, pero en "direcciones opuestas": "el etnólogo marcha hacia delante, tratando de alcanzar, a través de un consciente que jamás ignora, un sector cada vez mayor del inconsciente hacia el cual se dirige, mientras que el historiador avanza, para decirlo así, mirando hacia atrás, los ojos fijos en las actividades concretas y particulares, de las cuales se aleja únicamente para considerarlas desde una perspectiva más rica y más completa" (Lévi-Strauss, 1995, 71). Desde esta perspectiva, las diferencias entre los dos campos no llevarían a un antagonismo epistemológico sino a una complementariedad, tanto que el antropólogo francés termina por definirlos como "Jano bifronte". Sin embargo, más allá de la particular visión que Lévi-Strauss tiene de la historia, en gran parte influenciada precisamente por la Escuela de los Annales, los problemas que su propuesta suscitó y continúa suscitando no son pocos.

Primeramente, el problema de las estructuras $y$, en segundo lugar, el de sociedades frías y sociedades calientes. Sobre el primer asunto, la polémica que se desató apuntaba a varios aspectos: la existencia de estructuras, su función y, sobre 
todo, su presunta universalidad. Se trata, en verdad, de dos aspectos distintos aunque complementarios, que giran alrededor de la relación entre acontecimiento y estructura. Siguiendo a Braudel y su propuesta de distinguir por lo menos tres "duraciones", los acontecimientos son los que más rápidamente se trasforman, mientras las estructuras lo harian a una velocidad menor, en la "larga duración". Sin embargo, el valor semántico del concepto de estructura de Lévi-Strauss parece ser otro del considerado por Braudel:

\begin{abstract}
"Si, como creemos nosotros, la actividad inconsciente del espiritu consiste en imponer formas a un contenido, y si estas formas son fundamentalmente las mismas para todos los espíritus, antiguos o modernos, primitivos o civilizados -como lo muestra de manera brillante el estudio de la función simbólica, tal como se expresa en el lenguaje-, es necesario y suficiente alcanzar la estructura inconsciente que subyace en cada institución o cada costumbre para obtener un principio de interpretación válida para otras instituciones y otras costumbres a condición, naturalmente, de llevar lo bastante lejos el análisis" (Lévi-Strauss, 1995, 68).
\end{abstract}

Aquí estriba el núcleo central de la polémica: si las formas que el inconsciente da a los contenidos son "universales" y válidas para cualquier sociedad, del presente o del pasado, evidentemente estas formas no cambian, aunque la segunda parte de la cita deja entrever que podría tratarse de una "universalidad" interna a cada sociedad, sobre todo cuando se refiere a su utilización, una vez identificadas, para interpretar instituciones diferentes de aquélla que permitió la determinación ${ }^{8}$. Pero, frente a las equivocaciones que su propuesta produjo, Lévi-Strauss abandona un poco este aspecto de su definición de estructura, tendencialmente inmóvil y universal, en función de una definición más dinámica, haciendo explícita referencia a estructuras de comunicación y estructura de subordinación, lo que permite concluir a Gilles Granger, utilizando por ejemplo una cierta lectura de las Mitológicas, que se trata de "un movimiento constante de desestructuración y de reestructuración, inseparables de la estructura 'precaria', que es, pues, un proceso" (Granger, 1969, 28). Hablar de "proceso" en este contexto y relacionarlo con Lévi-Strauss parece una provocación. Sin embargo, es él mismo quien en $E I$ Pensamiento Salvaje afirma que:

"Las estructuras sólo aparecen a la observación practicada desde afuera $y_{1}$ en contrapartida, ésta no puede captar los procesos que se refieren a la manera particular en la que una temporalidad es vivida por el sujeto. Lo que equivale a decir que sólo existe proceso para el individuo implicado en su propio devenir histórico 0 , más exactamente, en el del grupo al que pertenece" (Lévi-Strauss, 1984, 44).

Reaparece aquí la diferencia de enfoque entre historiadores y antropólogos, por lo menos según Lévi-Strauss, en cuanto al estudio de procesos conscientes y estructuras inconscientes. Pero, precisamente, la referencia al concepto de "procesos" permite echar otro puente, este vez más operativo, entre antropología e historia, ya que de alguna manera permite la superación de la clásica "fijación" de las dos disciplinas sobre los hechos, como si éstos existieran en realidad como "objetos" y no fueran una construcción del observador, incluyendo a los investigadores. La referencia introduce también el otro polo de la polémica: la diferenciación entre sociedades frías y sociedades calientes, es decir, según la lectura vulgar, con y sin historia. La incomprensión fue máxima en la época. Esta vez no fueron los historiadores a reclamar, tan convencidos ellos de su implícito evolucionismo cultural y de su adhesión a las teoría de Lévi-Bruhl sobre mentalidades pre-lógicas y afines, sino los antropólogos, sobre todo los del campo marxista 9 .

Para responder a este y otros problemas de la polémica, Lévi-Strauss escribió un segundo texto con el mismo título que el primero, Etnología e historia, presentándolo en 1983 como conferencia en honor a Marc Bloch, precisamente uno de los padres de la llamada Nueva Historia. Aquí ridiculizaba un poco la interpretación que se habia hecho de su definición de sociedades frías y sociedades calientes, reafirmando que: "Todas las sociedades son históricas con el mismo grado, pero algunas lo admiten francamente mientras otras lo repugnan y prefieren ignorarlo" (Lévi-Strauss, 1988, 59). A partir de esto se pregunta cómo, en nuestras palabras, una sociedad que vive o intenta vivir en el presente, alejando de sí cualquier idea de pasado, puede "abrirse" a la historia y "cabalgarla", si se nos permite el uso de esta metáfora. Mejor: se pregunta, marxianamente nos parece, cuáles son "las condiciones y en qué formas se abren a la historia el pensamiento colectivo y los individuos" (idem). Para explicar este proceso, Lévi-Strauss recurre a ejemplos japoneses y samoanos, introduciendo el concepto de ideología:

ARBOR CLXXXVI 743 mayo-junio [2010] 377-392 ISSN: 0210-1963

(1)


"El llamar frías a las sociedades de este tipo lleva implícito que existe una distancia mínima entre su ideología y su práctica; o, como se creyó durante mucho tiempo, la primera es el fiel reflejo de la segunda; o la ideología disfraza la realidad, pero le inflige un pequeño número de distorsiones que se pueden enderezar fácilmente con la observación y el análisis". En las sociedades Ilamadas complejas o semicomplejas, la ideología se despega más de la infraestructura. Las distancias se amplian y se redistribuyen sobre varios ejes..." (Lévi-Strauss, 1988, 68).

El despegue puede originarse tanto de un acontecimiento que pone en estado de "turbulencia" el orden social local, así como de un cambio en las relaciones de producción, que determinan nuevos arreglos de poder. Precisamente, considerando un ejemplo del primer caso, la llegada del capitán Cook a Tahití, Marshall Sahlins elaboró su fundamental aporte contenido en el libro Islas de Historia (Sahlins, 1988).

Lo anterior es pensable en la medida que la vivencia diacrónica no sea percibida como continua sino como una serie discontinua. El pasado, así, más que la historia, hecha ésta por los historiadores desde su mirada y contexto social y cultural, se eslabonaría de forma discontinua, en sucesiones de sincronías que intentan apaciguar las turbulencias a través de sistemas de estabilización, como los ha llamado Hobsbawm; y cuando no lo consiguen, se transforman, precisamente por las contradicciones que no resuelven 0 , si se quiere, por el conflicto que conllevan las relaciones entre sujetos sociales de diferente género, posición social o poder. $Y$ estos sujetos, más que individuos, son grupos, estamentos $y$, finalmente, clases.

De ahí que, para Lévi-Strauss, y en polémica con Piaget y su epistemología genética, una vez negada la continuidad, el problema de los orígenes no tiene asidero epistemológico, salvo precisamente como identificación de tendencia de una sociedad específica que se busca en el pasado, que es lo mismo que decir que cada presente construye su pasado con fines ideológicos o simplemente identitarios. El pasado, así, es construido por el presente y "emerge", diria Foucault, a la conciencia de los individuos como Minerva con su yelmo y armadura de la cabeza de Zeus ${ }^{10}$.

Resumimos: la intención de Lévi-Strauss era la de introducir el concepto de inconsciente en las reconstrucciones históricas convencido, pero en gran parte equivocado, de que esa era también la dirección tomada por los nuevos historiadores de los Annales. Hablar de estructuras inconscientes en psicología o en antropología no era lo mismo que hablar de estructuras, por ejemplo, económicas, aun cuando estas últimas se producen sin la participación consciente de los individuos. Retorna aquí el problema del nivel de existencia de las estructuras: ¿formas estructurantes, ordenaciones virtuales, modelos, formaciones discursivas, como las Ilamará Foucault, ciclos?

Sin embargo, para entonces, y eran ya los años ochenta del siglo pasado, parafraseando a Burke, por segunda vez, aunque esta vez no tan repentinamente, "Ios antropólogos rompieron con el pasado". Me explico: la crisis del estructuralismo, así como del marxismo, sepultó el debate entre estructura y acontecimiento, y los antropólogos, ya en plena búsqueda posmoderna de soluciones a la crisis de la misma modernidad, centraron su atención en los relatos etnográficos, poniendo en duda su bases metodológicas, mientras el campo epistémico de su disciplina se fragmentaba en una multiplicidad de recorridos, perdiendo para siempre los asideros fuertes, totalizantes, que habian dado origen a la antropología que ya podía ser definida como clásica.

Además, al lado de los antropólogos intranquilos con su propio campo, otros continuaron reproduciendo su idea clásica de la disciplina sin percatarse mucho de que el contexto de producción de esa mirada ya había cambiado; lo mismo que muchos historiadores, comprometidos todavía con sus reconstrucciones de los "hechos" pasados, sobre todo políticos. Para todo ellos, continuó valiendo lo que Burke escribía en 1980:

"Tanto los sociólogos como los historiadores ven la paja en el ojo de su vecino. Por desgracia, cada grupo tiende a percibir al otro en términos estereotipados... Un contraste similar se ha establecido entre la tribu de los historiadores y la de los antropólogos. Desde un punto de vista histórico, está claro que las dos partes sufren de anacronismo. Parece que los sociólogos piensan que la historia todavía está en la fase de Ranke, narrativa sin análisis; mientras que para los historiadores es como si la sociología todavía estuviera en la fase de Comte, grandes generalizaciones sin investigación empírica" (Burke, 1987, 13). 
De cualquier manera, ingenuos unos o complicados los otros, los historiadores "intranquilos" insistieron en leer a los antropólogos y utilizar algunos de sus aportes, aunque con polémicas de un lado y del otro. Pensamos, por ejemplo, en el debate que se dio en el Journal of Interdisciplinary History, en 1975, sobre la utilización de ejemplos etnográficos por parte de Keith Thomas en su Religion and the Decline of Magic (1971), criticado por Hildred Geertz por "haber tomado, en palabras de Thompson, prestados enfoques de varias escuelas antropológicas dispares, cuando lo que se supone que tendria que haber hecho es haberse mantenido bajo la disciplina de una sola de ellas. Sin una disciplina teórica coherente tales préstamos revelan un oportunismo empírico o un mero amateurismo. La brujería debe ser explicada de esta o de aquella manera; no estamos autorizados a jugar con varias categorías de interpretación alternativas, tomadas de teorias antropológicas incompatibles" (Thompson, 1989, 81). El comentarista sin embargo está explícitamente del lado de Thomas, aunque está convencido de que "las categorías o modelos derivados de un contexto deben ser probados, refinados, y quizás reformados en el curso de la investigación histórica; por ello debemos ser cautos en su uso por el momento" (ídem), considerando que "el estímulo antropológico no surte su efecto en la construcción de modelos, sino en la localización de nuevos problemas, en la percepción de problemas antiguos con ojos nuevos..." (Thompson, 1989, 82). Sin embargo, aunque nos parece que recibir un estímulo para reconsiderar el planteamiento de los problemas a partir del aporte antropológico es deseable, permanece el problema de cómo construir conscientemente los datos sin una teoría explícita, ya que, como bien dijo Burke:

"Los historiadores tradicionales a menudo niegan que tengan alguna relación con los modelos, pero en la práctica muchos de ellos usan modelos, como M. Jourdain usaba la prosa, sin darse cuenta de ellos. Sin embargo, a pesar de que eviten la palabra 'modelo', se permiten utilizar términos generales como 'feudalismo' y 'capitalismo', 'Renacimiento' e 'llustración', o hablar sobre la forma 'clásica' o 'de libros de texto' de un fenómeno social como la manor (casa señorial) medieval. El utilizar modelos de esta forma, sin ser conscientes de su estatus lógico, a veces ha llevado a los historiadores a dificultades innecesarias" (Burke, 1987, 41).

La necesidad de explicitar la teoría o los modelos interpretativos en la recopilación de datos estriba precisamente en el hecho de que no hay percepción de la realidad inmediata y directa sino que siempre está mediada por las teorias implícitas de la sociedad del investigador, lo que es obligatorio "vigilar" precisamente a través de la producción de modelos teóricos conscientes. Como escribe Charles M. Radding en 1984, "la elección no es entre hechos y teoría, sino entre teoria consciente y teoría inconsciente" (Radding, 1989, 113). Sin embargo, lo que ha pasado, en la relación de muchos historiadores con la antropología, ha sido más una positiva consideración y aprehensión de las metodologías etnográficas, que una reflexión sobre la epistemología que las producian. En palabras de Radding:

"Lo que los historiadores han adoptado con entusiasmo son las metodologías, de las que parecen creer que pueden ser utilizadas independientemente de cualquier posición teórica sobre algo. Como el sexo sin matrimonio, es algo bonito cuando se consigue. Pero, como el sexo, las metodologías pueden llevar, voluntariamente o no, a responsabilidades y complicaciones imprevistas. Efectivamente, las metodologías no son simplemente, como parecen pensar a menudo los historiadores, modos de proceder en la recogida de los datos, ni siquiera valoraciones sobre la importancia de ciertos hechos. Las metodologías implican juicios sobre el nexo que une los hechos entre sí, que derivan de una precisa concepción de cómo funcionan las sociedades y de cómo piensa la gente" (Radding, 1989, 106).

En relación con este problema de la teoría en campo historiográfico, vale la pena citar la lectura que Giovanni Levi, uno de los más importantes miembros de la llamada microhistoria italiana, ha hecho de la obra del antropólogo Clifford Geertz, sobre todo a partir de su teoria de la "descripción densa" (Geertz, 1987), contenida en la antología de textos Formas de hacer historia, editada por Peter Burke (1993a). Después de aclarar que "las características de la microhistoria demuestran los lazos íntimos que ligan la historia a la antropología" (Levi, 1993, 126), el historiador italiano presenta las consideraciones de Geertz sobre las descripciones que los antropólogos realizan y su característica de "densidad", es decir, interpretativa, haciendo propio el concepto, pero sin llegar al extremo, como hace el antropólogo, de afirmar la imposibilidad de "formular sistemas intelectuales sin recurrir a la guía de modelos de emoción públicos y simbólicos, de manera que tales modelos son elementos esenciales utilizados para dar sentido al mundo" (Lévi, 1993, 129); lo que llevaría a la 
antropología interpretativa, según la lectura de Lévi, a "la renuncia a cualquier intento de construir modelos y establecer las reglas formales del juego de la interpretación y la comunicación" (Lévi, 1993, 134). Por esto, piensa que "una de las principales diferencias de perspectiva entre la microhistoria y la antropología interpretativa es que ésta ve significados en los signos y símbolos públicos, mientras que la microhistoria intenta definirlos y medirlos por referencia a la multiplicidad de representaciones sociales que generan" (Lévi, 1993, 132) ${ }^{11}$. Resulta interesante esta critica, entre otras sobre el relativismo, que un historiador formula a un antropólogo, ya que coincide con otras que a la antropología interpretativa y a la "descripción densa" han sido expresadas desde el mismo campo disciplinar, aunque a partir de otras corrientes antropológicas (Reynoso, 1995). De hecho, que las descripciones sean interpretativas lo sabíamos ya tanto antropólogos como historiadores y "el problema, como dice Lévi, reside más bien en cómo podriamos elaborar un paradigma que gire sobre el conocimiento de lo particular sin renunciar a la descripción formal y el conocimiento científico de ese mismo particular" (Lévi, 1993, 141).

Sobre estos aspectos de la relación entre antropología interpretativa e historia, también Burke interviene, en la misma antología citada, con un texto sobre Historia de los acontecimientos y renacimiento de la narración (Burke, 1993c), para matizar la fuerza totalizante de la propuesta de Geertz insinuando que así como hay "descripciones densas" lo mismo las hay "fluidas": "La narración, como la descripción, podría calificarse de más o menos 'fluida' o 'densa'. En el polo fluido del espectro tenemos la mera observación de un libro de anales, como los de la Crónica Anglosajona, donde se lee: 'En este año Ceowulf perdió su reino'. En el otro extremo hallamos relatos (demasiado escasos hasta el momento) construidos deliberadamente para soportar un gran peso interpretativo" (Burke, 1993c, 297). Más allá del hecho de que, por ejemplo, en el caso latinoamericano, los ejemplos de "narración densa", entendida de esta manera, existan en abundancia -basta pensar en los Cronistas de la conquista- tengo la sospecha de que la lectura de Burke se refiere solamente a un aspecto de la teoría de Geertz (la densidad de los "textos" expresados, es decir, la de los "guiños" de los actores social de Ryle) y menos a la descripción etnográfica (la densidad implícita en la descripción), como parece indicar cuando sugiere que las "micronarraciones" permitirian esa densidad, aunque la "reducción de escala no adensa de por sí una narración" (Burke, 1993c, 300).

En verdad, en la propuesta de Geertz, la "descripción densa" atañe sobre todo a la "interpretación", sea ésta de los actores sociales implicados en acontecimientos especificos, como la de los antropólogos, ocupados en describir etnográficamente (a menudo sin consciencia que están ya interpretando) y, después, interpretar etnológicamente. Escribe Geertz:

"El derecho de la relación etnográfica a que se le preste atención no depende de la habilidad que tenga su autor para recoger hechos primitivos en remotos lugares y llevarlos a su país, como si fueran una máscara o una escultura exótica, sino que depende del grado en que ese autor sea capaz de clarificar lo que ocurre en tales lugares, de reducir el enigma - ¿qué clase de hombres son ésos?- al que naturalmente dan nacimiento hechos no familiares que surgen en escenarios desconocidos... Si ésta es descripción densa y los etnógrafos son los que hacen las descripciones, luego la cuestión fundamental en todo ejemplo dado en la descripción (ya se trate de una nota aislada de la libreta de campo, o de una monografía de las dimensiones de las de Malinowski) es la de saber si la descripción distingue los guiños de los tics y los guiños verdaderos de los guiños fingidos. Debemos medir la validez de nuestras explicaciones, no atendiendo a un cuerpo de datos no interpretados y a descripciones radicalmente tenues y superficiales, sino atendiendo al poder de la imaginación científica para ponernos en contacto con la vida de gentes extrañas. Como dijo Thoreau, no vale la pena dar la vuelta al mundo para ir a contar los gatos que hay en Zanzibar" (Geertz, 1987, 29).

Pienso que, en vista de la periódica vuelta de la narración en el campo historiográfico, así como de la descripción etnográfica sin pretensiones interpretativas, por lo menos conscientes, o nomotéticas, se hace necesario volver a estos temas con la consciencia, como dice Reynoso en su crítica a Geertz: "Los hechos no hablan a menos que los interrogue una teoría, como los significados no proliferan a menos que actúe un método interpretante (expresable, comunicable y replicable en tanto método)..." (Reynoso, 1995, 22). 


\section{MiRadas Y CAMPOS DE ESTUdiOS: CONVERGENCIAS POSIBLES 0 IRREDUCTIBLES}

Como cualquier reconstrucción del pasado, la elaborada en las páginas anteriores es personal y deriva de dos criterios más o menos conscientemente elegidos: el primero se refiere a la búsqueda de asideros para valorizar una perspectiva disciplinar actual, aunque estos son asumidos como pretéritos, lo que implica producir un efecto de superación sin negación; el segundo deriva de una constatación, tal vez un poco exagerada, que, sin embargo, puede servir a los fines de nuestra discusión. En la historia de la relación, ya se dijo ambigua, entre antropología e historia, lo que quiere decir entre antropólogos e historiadores, las discrepancias han sido más pretexto para delimitar campos disciplinares y cuotas de poder universitario que real discusión sobre las diferencias epistemológicas.

Además, visto el desinterés de los antropólogos, para decirlo en términos coloquiales, la pelota quedó solamente en el campo de los historiadores, quienes continuaron en busca de teorías que dieran sentido a su eterna búsqueda de los "hechos", mirando esperanzados a los desentendidos colegas del campo limítrofe. El silencio de los antropólogos, a partir sobre todo de los años ochenta, les obligó a experimentar por su cuenta la utilización de textos más o menos clásicos de la antropología en búsqueda de ejemplos que sirvieran para entender e interpretar fenómenos superficialmente parecidos, pero producidos en contextos diferentes, lo que terminaba por banalizar la comparación ya que, como diría Lévi-Strauss, "un hacha, en cambio, no engendra nunca otra hacha". No son los objetos o los acontecimientos, cada uno con su contexto de sentido, los que son comparables, sino su representación (Lévi-Strauss, 1995, 52).

A esta misma conclusión parecen haber llegado también algunos historiadores sociales, aunque permanecen algunos problemas de coherencia epistemológica sobre la realidad que el término "representación" expresa. De cualquier manera, ha habido un intento, más o menos explícito, de construir modelos que dieran cuenta de realidades más o menos olvidadas por los historiadores políticos: "historia de las mentalidades", aunque las debilidades del término de Lévi-Bruhl son obvias; "historia de las sensibilidades", aunque hay un problema de transposición del mundo psicológico individual al mundo de lo social; y hasta "historia de las representaciones", término que, en su utilización historiográfica, confunde a menudo modelos culturales, discursos culturales y hasta ideologías. Ha sido tanta la fuerza de estos movimientos disciplinarios en el campo historiográfico que se le ha ido reduciendo el campo a los mismos antropólogos, tanto que cada vez más hay historiadores que se interesan por el presente, aunque esa definición de "historia instantánea" que algunos utilizan no es de las más felices.

Precisamente a partir de la última observación, vale la pena citar un aporte que pensamos importante para nuestro recorrido: un historiador que se interesa por el presente. Queremos referirnos a Carlo Ginzburg con su texto El juez y el historiador, sobre el caso Sofri (Ginzburg, 1993). Ginzburg ha desempeñado un rol fundamental en la producción del enfoque historiográfico llamado microhistoria, donde se han conjugado una reducción de escala en la delimitación de los objetos de estudio con una explícita referencia a la vivencia cultural de individuos y pequeños grupos humanos. Más allá de las críticas metodológicas, en parte acertadas, la investigación que lleva el nombre de El queso y los gusanos (1996) constituye un ejemplo importante de sensibilidad antropológica que hace de Menocchio un personaje no fácil de olvidar, más allá de que se trata de una "construcción" que tanto debe a los documentos inquisitoriales como a la trayectoria vivencial del mismo autor. Después de haber buceado a lo largo del pasado italiano y europeo de la temprana modernidad, con especial atención a los procesos inquisitoriales, y de haber sugerido la utilidad metodológica del Ilamado "paradigma indiciario", Ginzburg se siente impelido, por motivos declaradamente personales, a examinar las actas del largo proceso a Adriano Sofri, acusado de ser la mente detrás del asesinato del jefe de policía Calabresi, en los años setenta, italianos, llamados de "plomo". Es opinión compartida que los varios procesos contra Sofri han sido plagados de problemas de procedimiento y las actas registran con abundancia lo que Ginzburg, siguiendo las mismas requisitorias, define irónicamente como "pequeños errores" (Ginzburg, 1993, 28). No viene al caso aquí discutir los resultados de estas indagaciones, sino apuntar a que un material documental del presente es sometido al análisis de un experto en documentos del pasado. Valdría aquí la pregunta sobre cuál sería la diferencia entre esta mirada microhistórica y la del antropólogo, ya que este último, en su lugar, analizaría los documentos del proceso, vería las 
grabaciones de las diferentes sesiones, leería los periódicos y, sobre todo, escucharía lo que la gente común tiene que decir sobre el caso. Esto es precisamente lo que Ginzburg ha hecho y con buenos resultados.

En verdad, y en esta investigación sobre todo, Ginzburg parece ser consciente de que su mirada se ha ampliado. Así, rememorando la tradición antigua que ve el trabajo del historiador homólogo al del juez, Ginzburg pone su experiencia en el análisis de los procesos inquisitoriales al servicio de un examen de las actas de un procedimiento contemporáneo a su misma vivencia. Sin embargo, no en el sentido estricto de la homología citada: "El modelo judicial tuvo dos efectos interdependientes sobre los historiadores. Por una parte les indujo a centrarse en los acontecimientos (políticos, militares, diplomáticos) que en cuanto tales podían ser atribuidos sin demasiadas dificultades a la actuación de uno o más individuos; por otra, a descuidar todos los fenómenos (historia de los grupos sociales, historia de las mentalidades y así sucesivamente) que no encajaban en esta pauta explicativa" (Ginzburg, 1993, 20). Aunque puede parecer reductivo, nos parece que lo que esa historiografía se olvidaba es precisamente del objeto de estudio de la antropología, es decir, la cultura. De hecho, el mismo Ginzburg, paseándose por los ejemplos de la historiografía de los Anales, hace referencia a los "acontecimientos fantasmales", "la imagen que de ellos se hacía una miriada de individuos anónimos" (Ginzburg, 1993, 21), haciendo hincapié en su "eficacia simbólica", término precisamente empleado por Lévi-Strauss en un texto con este mismo título contenido en su Antropología estructural. En verdad, Ginzburg se está refiriendo a las "representaciones", concepto muy utilizado por los antropólogos desde por lo menos el mismo Durkheim, y que los historiadores franceses y norteamericanos han puesto en auge, aunque a menudo olvidando la necesidad de anclarlas en una realidad etnográfica concreta. Como escribe Ginzburg, y esto vale también para los antropólogos interpretativos:

"La fuente histórica tiende a ser examinada exclusivamente en tanto que fuente de sí misma (según el modo en qué ha sido construida), y no de aquello de lo que se habla. Por decirlo con otras palabras, se analizan las fuentes (escritas, en imágenes, etcétera) en tanto que testimonios de 'representaciones' sociales; pero al mismo tiempo se rechaza, como una imperdonable ingenuidad positivista, la posibilidad de analizar las relaciones existentes entre estos testimonios y la realidad por ellos designada o representada. Pues bien, estas relaciones nunca son obvias: definirlas en términos de representación sí que sería ingenuo. Sabemos perfectamente que todo testimonio está construido según un código determinado: (alcanzar la realidad histórica o la realidad) directamente es por definición imposible. Pero inferir de ello la incognoscibilidad de la realidad significa caer en una forma de escepticismo perezosamente radical que es al mismo tiempo insostenible desde el punto de vista existencial y contradictoria desde el punto de vista lógico: como es sabido, la elección fundamental del escéptico no es sometida a la duda metódica que declara profesar" (Ginzburg, 1993, 22-23).

Resulta interesante constatar que a las mismas conclusiones había llegado un antropólogo que se ha interesado del pasado, como es el caso de Marshall Sahlins y su reconstrucción de la muerte del capitán Cook en Tahití en 1778 (Sahlins, 1988). Retomando la discusión sobre acontecimiento y estructura, Sahlins se pregunta en qué relación se encuentran los dos términos, llegando a la conclusión de que "el acontecimiento es una relación entre un suceso y una estructura (o varias estructuras): un englobamiento del fenómeno en sí mismo como valor significativo, del que se deduce su eficacia histórica especifica", proponiendo interponer "un tercer término entre estructura y el acontecimiento: la sintesis situacional de los dos en una 'estructura de la coyuntura'" (Sahlins, 1988, 14). De manera explícita el concepto de coyuntura difiere un poco del de Braudel, ya que se trataría de "la realización práctica de las categorías culturales en un contexto histórico específico, como se expresa en la acción interesada de los agentes históricos, incluida la microsociología de su interacción" (ídem). La cercanía con la postura de Ginzburg es evidente, lo que hace posible delimitar un campo interesante de interacción entre las dos miradas disciplinares a partir, esta vez, de dos epistemologías conmensurables, donde la atención a la realidad de los procesos tiene en cuenta tanto la materialidad de las interacciones como las representaciones que de ellos se hacen culturalmente individuos o grupos, dando por adquirida y necesaria la noción de inconsciente ${ }^{12}$.

Ésta nos parece la misma dirección indicada por Burke en varias de sus obras, sobre todo cuando, identificando las deficiencias del funcionalismo, advierte del "peligro de estudiar la vida social desde fuera sin tener en cuenta las intenciones de los 'actores' o sus definiciones de la situación" (Burke, 1987, 31), además de estar convencido que 
"el cambio está estructurado, y las estructuras cambian" (Burke, 1987, 11). Y, finalmente, describe de la siguiente manera, a comienzo de los noventa, la perspectiva de los historiadores sociales, entre los cuales se adscribe:

"Lo común a estas formas de abordar la cuestión es su interés por el mundo de la experiencia ordinaria (más que por la sociedad en abstracto) en cuanto punto de partida, junto con un empeño por considerar problemática la vida diaria, en el sentido de mostrar que el comportamiento o valores dados por supuestos en una sociedad se descartan como en otra como evidentemente absurdos. Ciertos historiadores, al igual que los antropólogos sociales, intentan en la actualidad desvelar las reglas latentes de la vida cotidiana (la 'poética' de cada día, en expresión del semiólogo ruso Juri Lotman) y mostrar a sus lectores cómo se es padre o hija, legislador o santo en una determinada cultura. En este punto, la historia social y cultural parecen disolverse la una en la otra. Algunos de quienes las practican se describen como 'nuevos' historiadores de la cultura; otros como historiadores 'socioculturales'. En cualquier caso, el impacto del relativismo cultural en la historiografía parece ineludible" (Burke, 1993b, 25).

Evidentemente, nos encontramos en un ambiente que podemos bien definir como antropológico, entendiendo con esta caracterización: (a) la vida social y cultural como objeto de estudio, con atención a las prácticas sociales y a las representaciones culturales; (b) una atención metodológica particular a las "voces" de los actores sociales, es decir, atención a la vivencia y a las ideas que alrededor de ella circulan en la sociedad local; (c) un interés tanto por las ideas conscientes como por los niveles inconscientes que las definen; y (c) la necesidad de una teoría previa, aunque no constrictiva, del objeto elegido. Burke, en su análisis de la "historia de las mentalidades", corrobora de alguna manera nuestras conclusiones cuando identifica características similares en esta corriente que también propone definir como "antropología histórica de las ideas" (Burke, 2006, 208). Sin embargo, precisamente esta referencia a las "ideas" lo hace afirmar críticamente que "la primera observación que cabe hacer sobre la historia de las mentalidades es que algo debe ocupar el espacio conceptual entre historia de las ideas e historia social a fin de no tener que elegir entre una historia intelectual que excluye a la sociedad y una historia social que excluya el pensamiento" (Burke, 2006, 210). A estas críticas añade otras -la sobrevalorización de la homogeneidad social, la poca atención al cambio social, la implícita creencia en la autonomía de las representaciones, su evolucionismo y etnocentrismo (Burke, 2006, 217-222)- que, en positivo, diseñan una disciplina que podriamos bien llamar "antropología histórica", a secas. De hecho, el mismo Burke, recorriendo los problemas y alcances de la "Historia cultural", sugiere implícitamente su necesaria transformación en "historia antropológica" (Burke, 2006, 241). Asumiendo esta sugerencia y ampliándola, podriamos llegar a la conclusión de que todos estos enfoques pueden desembocar en una disciplina unitaria con dos vertientes: una antropología histórica que se interese de estudiar la sociedad en su "sincronía", cruzando los niveles estructurales con los conformados por los acontecimientos; y una historia antropológica que apunte su mirada hacia los cambios sociales y culturales, intentando una explicación antropológica de los mismos, sin desvalorizar el impacto de los cambios económicos y políticos y, naturalmente, las experticias historiográficas que sobre estos se han producido.

Esta confluencia disciplinar no puede pasar por alto el problema de la diferencia de método, sobre todo en cuanto se refiere al Ilamado "trabajo de campo" de los antropólogos, es decir, la convivencia con la gente investigada (o "en que se estudia", para recordar la proposición de Clifford Geertz) que definiria la diferencia metodológica entre la disciplina historiográfica y la antropológica. Volvemos asi al comienzo de nuestro recorrido, al Malinowski que teorizaba el método antropológico descalificando los métodos historiográficos de conocimiento de la realidad social y cultural. No cabe duda de que el impacto emocional de la convivencia favorece la producción de una sensibilidad especial hacia la diferencia, que es base de cualquier mirada relativista, permitiendo no sólo ver a los otros en acción, sino también percibir con mayor facilidad la manera en que los actores miran su mundo y el mundo de los demás. En este sentido, y a fines sobre todo didácticos, una previa experiencia antropológica de campo para cualquier historiador podría redundar en una mayor capacidad de comprensión de la diversidad temporal ya que, como escribe Burke, "la cuestión es que para comprender el comportamiento de la gente de otras culturas no basta con ponerse en su situación; también es necesario imaginar su definición de la situación, verla a través de sus ojos" (Burke, 2006, 216) ${ }^{13}$.

Sin embargo, ante la importancia de lo anterior, cabe también observar que, a fin de cuentas, lo que el antropólogo

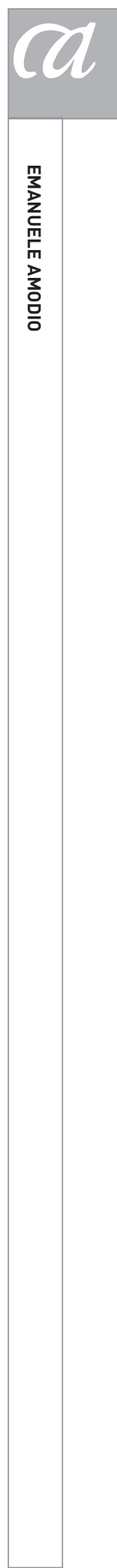


analiza, cuando finalmente redacta su "informe" en su despacho son "textos": de sus informantes, de la gente común y, es útil recalcarlo, de él mismo cuando tomaba notas durante su investigación participante. Claro que hay que distinguir, de alguna manera, el estatuto semiótico de un texto emitido oralmente de uno elaborado a través de la escritura, como es el caso de los documentos de archivos utilizados por los historiadores. Pero, precisamente la conciencia de la diferencia, dentro de una homologación posible, permite estructurar una metodología de análisis común, por ejemplo recurriendo a la semiótica, sobre todo teniendo en cuenta los niveles diferentes de mediación que pueden producirse, en un caso o en el otro, entre hablantes y redactores de textos más o menos profesionales. Esto implica tener siempre en cuenta que las miradas de los actores, desde adentro, son igual de importantes que las miradas desde afuera, sean estas de actores de otras culturas 0 , de manera antropológica, de otros que delimitan espacios de observación tendencialmente emancipados del "sentido común" de su sociedad, el "lugar del afuera", como diría Foucault (Amodio, 2005).
Así, en esta época que reclama, cada vez más, una multiplicidad de miradas o, como escribía Burke, citando a Mijail Bajtin, al final de su Formas de historia cultural (Burke, 2006, 264), una "visión polifónica", frente al multiplicarse de las realidades culturales que aparecen con fuerza en el horizonte historiográfico del Occidente, espero llegado el momento de cerrar el círculo que nunca tendría que haberse abierto entre historia y antropología, recuperando la posibilidad de cruzar métodos e intenciones. Fue así como, en el lejano 1949, lo auspiciaba Lévi-Strauss:

\begin{abstract}
"Hasta el presente, una distribución de tareas justificada por antiguas tradiciones y por las necesidades del momento ha contribuido a confundir los aspectos teóricos y prácticos de la distinción, y de esa manera a separar más de lo conveniente la etnologia de la historia. Sólo cuando ambas aborden conjuntamente el estudio de las sociedades contemporáneas, se podrán apreciar plenamente los resultados de su colaboración y se llegará a la convicción de que, en ese caso como en los demás, nada puede la una sin la otra" (Lévi-Strauss, 1995, 72).
\end{abstract}

\section{NOTAS}

1 Sobre los hechos citados, véase la entrevista que Peter Burke concedió a Claudia Möller en 1996 durante su visita a Argentina, invitado por el Programa de Maestría en Historia de la Facultad de Humanidades, de la Universidad Nacional de Mar del Plata (http://clio.rediris.es/entrevistas/peter_burke.htm).

2 Hay que recordar que, en la misma época que Malinowski teorizaba sobre el trabajo de campo en las primeras páginas de Argonautas (Malinowski, 2001), en Francia Marcel Mauss elaboraba cuestionarios etnográficos para la recolección de datos de campo, los que confluirán en su Manual de Etnografía, publicado en 1926, y cuyo primer capítulo se titulaba precisamente "Méthodes d'observation" (Mauss, 1967).

Recibido: 1 de diciembre de 2008

Aceptado: 1 de mayo de 2009
3 La cita de Malinowski pertenece al capítulo tercero de su obra de Dynamics of Culture Change (New York, 1946).
4 Sobre el tema de la función desempeñada por las "imágenes" del pasado, los antropólogos funcionalistas ingleses no ahondaron mucho, hasta por lo menos el seminario organizado por Eric Hobsbawm y Terence Ranger sobre este tema (Hobsbawm y Ranger, 1983).

5 Resulta interesante acotar que, en esa misma década, Julio Caro Baroja recorría en España los mismos senderos entre antropología e historia, sugiriendo precisamente una postura antropológica funcionalista en el estudio del pasado, a fin de superar el morfologismo de la descripción historiográfica, como bien expresa en su artículo "La investigación histórica y los métodos de la etnología (morfología y funcionalismo)", publicado en la Revista de Estudios políticos, en el N. 80 del año 1955 (Castilla Urbano, 1993 y 1994).

6 Ya que los dos autores no se citan en sus respectivos textos sobre la relación entre historia y antropología, aunque 
el parentesco de sus posiciones es evidente, cabe la duda si hubo o no conocimiento de las posturas teóricas del otro. A falta de datos, vale la pena indicar las fechas de publicación de los diferentes textos que utilizamos como referencia: de Evans-Pritchard, Pasado y presente es una conferencia de 1950, mientras Antropología e historia lo es de 1961; de Lévi-Strauss, el texto Etnología e historia es de 1949, publicado en la Revue de Métaphysique et de Morale. Pareciera así que el antropólogo inglés tuvo posibilidad de leer el texto del francés. Sin embargo, hay que tener en cuenta que el texto de Lévi-Strauss tendrá su verdadera resonancia solamente después de que fuera reeditado en 1958 como primer capítulo del libro Antropología estructural (Lévi-Strauss, 1995). De alguna manera, también en el caso de EvansPritchard, pasó lo mismo, aunque con menor peso, ya que los dos textos citados fueron publicados en 1962 en la antología Ensayos de Antropología Social (Evans-Pritchard, 1990).

7 Resulta útil acotar que Lévi-Strauss ha sido un constante lector de la obra de los historiadores de los Anales, sobre todo en los años inmediatamente posteriores a la segunda guerra mundial. Véase, por ejemplo, la referencia al libro de Lucien Febvre, Probléme de I'incroyance au XVI siécle, citado como ejemplo de historia cercana a la antropología (Lévi-Strauss, 1995, 71) y la misma invitación a participar en 1983 en las Conférences-Marc Bloch, de la École des hautes études en sciences sociales.

8 Es importante resaltar que las equivocaciones, producidas también por el uso ambiguo de ciertas definiciones del mismo Lévi-Strauss, se refieren también a la existencia empírica o virtual de la estructura. Así, en La no- ción de estructura en etnología, texto contenido en la misma Antropología estructural, Lévi-Strauss escribe: "El principio fundamental afirma que la noción de estructura social no se refiere a la realidad empírica, sino a los modelos construidos de acuerdo a ésta" (Lévi-Strauss, 1995, 301), distinguiendo tajantemente la noción de estructura de la relaciones sociales.

9 A propósito de la polémica sobre sociedades frías y sociedades calientes, en la entrevista que Viveiros de Castro le hizo a Lévi-Strauss a final de los años noventa, éste declaraba sobre la confusión entre su categorización y la de sociedades con o sin historia: "Porque nadie se dio al trabajo de reflexionar. Existía una vieja distinción, pueblos con historia y pueblos sin historia, entonces ellos dicen que mi distinción es idéntica a ésa... ¡Fueron ellos que congelaron esas sociedades no yo!". Y añade: "Nos dicen que esas sociedades [indígenas americanas] no son diferentes de la nuestra, que ellas tienen la misma historia que la nuestra, etc., ésta no es absolutamente la cuestión. Lo que pedíamos a esas sociedades que estudiábamos es que ellas no nos debiesen nada: que ellas representasen experiencias humanas completamente independientes de la nuestra. A parte de esto, ellas pueden tener todas las historias que se quiere, pero ésta no es la cuestión. ¿Nos deben ellas lo que son, o no? Si ellas nos deben, ellas nos interesan moderadamente: si ellas no nos deben, ellas nos interesan apasionadamente" (Viveiros de Castro, 1998, 119 y 121).

10 Sobre este tema, asumiendo explícitamente la postura de Foucault, escribe Burke en 1997: "Si queremos evitar la atribución anacrónica de nuestras intenciones, intereses y valores a los muertos, no podemos escribir la histo- ria continuada de nada. De una parte, nos arriesgamos a imponer a nuestro objeto los esquemas del presente; de la otra, a no poder escribir nada en absoluto. Quizá hay un camino intermedio, un enfoque del pasado que plantee cuestiones derivadas de nuestros esquemas actuales, pero no dé respuestas inducidas por los mismos; que se ocupe de las tradiciones, pero deje margen para su continua reinterpretación, y que tenga en cuenta la importancia de las consecuencias no intencionales en la historia de la escritura histórica además de en la historia política" (Burke, 2006, 16).

11 Sobre el trabajo etnográfico, afirma Clifford Geertz: "Lo que en realidad encara el etnógrafo (salvo cuando está entregado a la más automática de las rutinas que es la recolección de datos) es una multiplicidad de estructuras conceptuales complejas, muchas de las cuales están superpuestas o enlazadas entre sí, estructuras que son al mismo tiempo extrañas, irregulares, no explícitas, y a las cuales el etnógrafo debe ingeniarse de alguna manera, para captarlas primero y para explicarlas después. Y esto ocurre hasta en los niveles de trabajo más vulgares y rutinarios de su actividad: entrevistar a informantes, observar ritos, elicitar términos de parentesco, establecer límites de propiedad, hacer censo de casas... escribir su diario. Hacer etnografía es como tratar de leer (en el sentido de 'interpretar un texto') un manuscrito extranjero, borroso, plagado de elipsis, de incoherencias, de sospechosas enmiendas y de comentarios tendenciosos y además escrito, no en las grafías convencionales de representación sonora, sino en ejemplos volátiles de conducta modelada" (Geertz, 1987, 24). La referencia al "manuscrito extranjero, borroso" pa- 
rece acercar, más allá de las intenciones del antropólogo norteamericano, el trabajo del antropólogo con el del historiador. Sin embargo, aunque Geertz no se haya interesado directamente de sociedades pretéritas, parece tener una resistencia a aceptar esta homología, sobre todo considerando el hecho que la "distancia", temporal en un caso, espacial en el otro, no unifica las dos "otredades", ya que en el caso del pasado, "el Otro se nos aparece como ancestral" (Geertz, 1992, 58).

12 A propósito de Sahlins y del capitán Cook, escribe Burke: "Sahlins nos ha contado una historia con moraleja 0 , quizá, con dos moralejas. La destinada a los 'estructuralistas' es que deberian reconocer el poder de los acontecimientos, su lugar en el proceso de 'estructuración'. Por otra parte, los defensores de la narración son estimulados a examinar la relación entre los acontecimientos y la cultura en que suceden. Sahlins ha ido más allá de la famosa yuxtaposición de Braudel entre acontecimientos y estructuras. De hecho ha resuelto, o disuelto, la oposición binaria entre estas dos categorías" (Burke, 2006, 304).

13 Escribe Marc Augé: "Todo lo que aleja de la observación directa del campo, aleja también de la antropología, y los historiadores que tienen intereses antropológicos no por eso hacen antropología" (Augé, 1993, 16). Precisamente nuestra sugerencia pretende superar esta apreciación.

\section{BIBLIOGRAFÍA}

Amodio, Emanuele (2005): "Extranjero en un país ajeno: Construcción del pasado y realidad histórica desde una perspectiva antropológica", Revista Venezolana de Economía y Ciencias Sociales, 11(2): 141-157.
Augé, Marc (1993): Los no lugares. Una antropología de la sobremodernidad, Barcelona, Gedisa.

Braudel, Fernand (1995): La historia y las ciencias sociales, Madrid, Alianza Editorial.

Burke, Peter (1987): Sociología e historia, Madrid, Alianza Editorial (Nueva edición, reelaborada parcialmente: History and Social Theory, Cambridge, Polity Press, 1992).

Burke, Peter (1993b): "Obertura: la nueva historia, su pasado y su futuro", Peter Burke (ed.), Formas de hacer historia, Madrid, Alianza Editorial, pp. 11-37.

Burke, Peter (1993c): "Historia de los acontecimientos y renacimiento de la narración", Peter Burke (ed.), Formas de hacer historia, Madrid, Alianza Editorial, pp. 287-306.

Burke, Peter (1999): La revolución historiográfica francesa, Barcelona, Gedisa.

Burke, Peter (2006): Formas de historia Cultural, Madrid, Alianza Editorial.

Burke, Peter (ed.) (1993a): Formas de hacer historia, Madrid, Alianza Editorial.

Castilla Urbano, Francisco (1993): "Sobre la 'Nueva Historia': autobiografía, biografía e historia de vida en la obra de Julio caro Baroja", Antropología. Revista de Pensamiento Antropológico y estudios Etnográficos, 4-5: 163-192.

Castilla Urbano, Francisco (1994): "El análisis histórico y antropológico de las minorias en la obra de Julio Caro Baroja", Cuadernos Hispanoamericanos, 533-534: 83-98.

Evans-Pritchard, Edward Evan (1990): Ensayos de antropología social, Madrid, Siglo XXI.

Geertz, Clifford (1987): La Interpretación de las Culturas, Barcelona, Gedisa.

Geertz, Clifford (1992): "Historia y antropología", Revista de Occidente, 137: 55-74.

Ginzburg, Carlo (1993): El juez y el historiador, Madrid, Anaya y Mario Muchnik.

Ginzburg, Carlo (1996): El queso y los gusanos, Barcelona, Atajos.
Granger, Gilles (1969): "Acontecimiento y estructura en las ciencias humanas", Varios Autores, Estructuralismo e historia, Buenos Aires, Ediciones Nueva Visión, pp. 7-44.

Hobsbawm, Eric y Terence Ranger (1983): The Invention of Tradition, Cambridge, University Press.

Levi, Giovanni (1993): "Sobre microhistoria", Peter Burke (ed.), Formas de hacer historia, Madrid, Alianza Editorial, pp. 119-143.

Lévi-Strauss, Claude (1984): El pensamiento salvaje, México, Fondo de Cultura Económica.

Lévi-Strauss, Claude (1988): "Etnología e historia", Anuario de etnología y antropología social, 1, 58-74, México.

Lévi-Strauss, Claude (1995): Antropología estructural, Barcelona, Paidós.

Malinowski, Bronislaw (2001): Los argonautas del Pacífico Occidental, Madrid, Ediciones Península.

Mauss, Marcel (1967): Manuel d'ethnographie (1926), Paris, Éditions sociales.

Radding, Charles M. (1989): "Antropología e historia, o el traje nuevo del emperador", Historia social, 3: 103-114.

Reynoso, Carlos (1995): "El lado oscuro de la descripción densa", Revista de Antropología, X-16: 17-43.

Sahlins, Marshall (1988): Islas de historia, Barcelona, Gedisa.

Skidmore, Thomas E. (2003): "Levi-Strauss, Braudel, and Brazil: A Case of Mutual Influence", Bulletin of Latin American Research, 22(3): 340-349.

Thomas, Keith (1971): Religion and the Decline of Magic, London, Weidenfeld \& Nicolson.

Thompson, E. P. (1989): "Folklore, antropología e historia social", Historia social, 3: 81-102.

Viveiros de Castro, Eduardo (1998): "LéviStrauss nos 90. A antropología de cabeça para baixo (Entrevista)", Mana, 4(2): 119-123. 